\title{
Pragmatics in EFL Teaching: Building Meaning beyond Words through the Use of Videos
}

\author{
Cinthya Olivares Garita \\ Sede Brunca \\ Universidad Nacional, Costa Rica \\ Lena BarRantes Elizondo \\ Sede Brunca \\ Universidad Nacional, Costa Rica
}

\begin{abstract}
Pragmatics, a seemingly unexplored area by most EFL teachers nowadays, offers a number of language competencies in order to convey and understand meaning successfully. It is worth mentioning that an EFL setting does not usually provide the same availability of opportunities to practice pragmatics as an ESL setting does. Thus, contextual cues, for this particular study, will be provided by audio-visual aids. This authentic material certainly displays the connotative meaning of words and phrases and the degree of appropriateness that have currently been downplayed in EFL scenarios by the over teaching of syntactic knowledge, mostly. Grounded on these premises, this qualitative study emerged. It was conducted with freshman and junior students of the English majors at Universidad Nacional of Costa Rica, Brunca Branch as an attempt at identifying the treatment pragmatics has received in the oral expression courses, and devising several techniques on how to help students grasp the connotative meaning of words and phrases derived from contextual factors found in authentic audio-visual aids.
\end{abstract}

Key words: pragmatics, context, authentic material, connotation, EFL

\section{Resumen}

La pragmática, un área que pareciera no ser explorada por muchos profesores de inglés como lengua extranjera hoy en día, ofrece un número de competencias lingüísticas que ayudan a expresar y entender el significado exitosamente. Un ambiente de aprendizaje de este tipo no 
provee la misma disponibilidad de oportunidades para practicar la pragmática como lo es un ambiente de aprendizaje del inglés como segunda lengua. Para este estudio en particular, se propuso un contexto a partir del uso de recursos audiovisuales auténticos. Este material contiene el significado connotativo de las palabras y frases, así como el grado de conveniencia que ha sido actualmente subestimado debido a la sobreenseñanza del conocimiento sintáctico. Este estudio cualitativo emerge fundamentado en estas premisas. Se llevó a cabo con estudiantes de primer y tercer año de las carreras de inglés de la Universidad Nacional de Costa Rica, Sede Regional Brunca, como un intento de identificar el tratamiento que ha recibido la pragmática en los cursos de expresión oral, y así también desarrollar varias técnicas para ayudar a los estudiantes a comprender el significado connotativo de las palabras y frases derivadas de factores contextuales encontrados en recursos audiovisuales auténticos.

Palabras claves: pragmática, contexto, material auténtico, connotación, inglés como lengua extranjera

\section{Introduction}

$\mathrm{D}$ espite the significance of the role of pragmatics in EFL learning, there is no evidence of research done in this field of language in the aforementioned university campus. The English teaching major started in 1997, but no records on pragmatic studies are found. The study described here developed an analysis on the teaching of connotative meaning of words in early stages of language learning through authentic material, videos in this case, with the ultimate goal of proposing a framework for learners and teachers. It involves an assessment of some class practices with emphasis on oral communication and an introspection of professors and students' perspectives.

Universidad Nacional, Brunca Branch (UNA, SRB) is one of the two state universities in the South Pacific in Costa Rica and the research context for this study. Its main campus is located in a transforming area that, little by little, is developing from rural to urban. A smaller campus is near the border with Panama. The labor market of this southern region is currently shaped by the social demands of effective communication skills, establishing the English language as a priority. An extensive variety of ecotourism possibilities and a majority of North American visitors led the community to pursuit high levels of compromise to obtain international incomes at all cost. This social commitment has put a heavy burden on this university administrators' shoulders. To satisfy this socio-economic demand, people in the community must consider effective English programs available. UNA, SRB offers two specialized English programs which are the English Teaching Major and the Associate's Program in English along with a language school. Nevertheless, speaking this language is not enough; on the contrary, to be effective speakers people must be able to understand what is behind each spoken word, and here is where pragmatics takes prominence in EFL instruction. 


\section{Literature Review}

The role of pragmatics in the EFL classroom has been downplayed. This study entails significant information to unearth the relevance of this element of the construct of communicative competence. There is a solid body of research that shows the significance of the teaching of pragmatics to foreign language learners.

\subsection{Definition of Pragmatics}

To understand language as a dynamic process, different aspects such as morphology, syntax, semantics, and pragmatics are necessary for a more comprehensive analysis. Recently, the study of pragmatics has gained more prominent importance since the mastery of vocabulary and structures have proved to be shallow if taught separately. There is more to the simple understanding of lexicon and grammar rules. Learners of a second or foreign language need to explore the other stadiums of language with the same precision and frequency. They need to move from the understanding of semantics to a more refined comprehension of what pragmatics accounts for.

Pragmatics is regarded as "the study of people's comprehension and production of linguistic action in context" (Kasper, 1993, p. 3). This concept puts a great premium on the interpretation interlocutors make of the message conveyed in the actual setting the conversation occurs. Context is key to the many interpretations a speaker can make of words and phrases. In other words, context carries meaning to decode the information from a more sociolinguistic point of view. Crystal (as cited in Barron, 2003) defined pragmatics as "the study of language from the point of view of the users, especially of the choices they make, the constraints they encounter in using language in social interaction, and the effects their use of language has on the other participants in an act of communication" (p. 276). Pragmatics is enclosed into the construct of communicative competence. Thus, speakers who aim to understand and be understood appropriately should possess some knowledge about how to interact by knowing what to say, how to say it and when to say it through the ability to imply meaning in context. The utmost concern of pragmatics is not only the mere understanding of grammatical correctness but also the fulfilment of appropriateness and naturalness within a given context.

\subsection{Elements Included in Pragmatics}

Pragmatics as the study that analyzes the ability that speakers develop to imply meaning beyond words is composed of several elements such as presupposition, deixis, speech acts and implicature among others. For the development of this study, these four pragmatic categories are specified.

\subsubsection{Presupposition}

As one pragmatic element, presupposition plays a significant role in everyday interaction. Potts (2014) shined a light on this term and defined it as "the pieces of information that the speaker assumes (or acts as if she assumes) in order for her utterance to be meaningful in the current context" (p.3). Prior to stating an utterance, there is valuable information 
the speaker assumes to be or not to be true. With regard to this, there are two different types of presuppositions: pragmatic and semantic. The former is purely speaker actions whereas the latter refers to conventional aspects of the meanings of specific words and constructions (idem).

Pragmatic presuppositions enclose "the preconditions for linguistic interaction, the norms of turn-taking in dialogue, and more particularized information about conversational plans and goals" (idem). This author alluded that semantic presuppositions entail "the encoded meanings of specific words and constructions called triggers" (p.4). In a similar vein, Stalnaker (1999) stated some detailed examples of presuppositions. He determined that "if I say that the Queen of England is bald, I presuppose that England has a unique queen, and asserted that she is bald. If I say that Sam regrets that he voted for Nixon, I presuppose that Sam voted for Nixon, and assert that he feels bad about it" (p.47). On this account, learners of a foreign language need the guide of the instructor to presuppose information at the moment of speaking, what to say or what to ask.

\subsubsection{Deixis}

Apart from contextual clues, language references contribute to deciphering the message speakers conveyed. Deixis stands for the associations made between the language and the context represented through some particles of language. An essential link is built around the real life environment and what is said. Expressions like I, we, you, this, that, here, there, now, yesterday, next year are all necessary to infer the speaker's message. From Yule's standpoint (1996)

Deixis is a technical term (from Greek) for one of the most basic things we do with utterances. It means 'pointing' via language. Any linguistic form used to accomplish this "pointing is called a deictic expression. When you notice a strange object and ask, 'What's that?' you are using a deictic expression ('that') to indicate something in the immediate context. (p. 9)

For speakers to contribute to the flow of communication, avoid misunderstandings and communication breakdowns, knowledge about the different types of deixis is crucial. These types are categorized as person deictic, spatial deictic and temporal deictic. The pointing language serves as indicators that guide the speakers throughout the route of the message until achieving a successfully complete conversation.

\subsubsection{Speech Acts}

From Yule's perspective (1996), speech acts are defined as "actions performed via utterances" (p. 47). This pragmatic element exerts great importance on the message sent. Actually, whenever a person expresses something, the message conveyed takes the form of an action. Yule (1996) threw light upon this premise by declaring that:

In attempting to express themselves, people do not only produce utterances containing grammatical structures and words, they perform actions via those utterances. If you work in a situation where a boss has a great deal of power, then the boss' utterance of the 
expression in [I] is more than just a statement. [I] You're fired. The utterance in [I] can be used to perform the act of ending your employment. (p. 47)

These actions are given specific names such as apology, denial, request, compliment, argument, excuse, greet, complaint, promise, among many others. All these actions conform to the choice of the speaker's intention at the moment of expressing a message.

\subsubsection{Implicature}

Implicatures are part of everyday conversations. To imply meaning the speaker requires some prior cultural knowledge. This knowledge determines how effective a speaker would be at inferencing meaning beyond words. Implicature guarantees the achievement of the four maxims according to Grice's ground-breaking theory of Cooperative Principle (cited in Derakhshan et all, 2014, p.13). The four maxims of Quality, Quantity, Relevance and Manner dictate that "the participants involved in a social interaction are expected to speak truthfully, sufficiently, relevantly and clearly" respectively (idem). If any of these principles is violated, the interlocutors may be required to transcend beyond what is said literally.

According to Derakhshan (2014), implicature is regarded as "the characteristic of the speaker's utterance through which what the speaker means go far beyond what he exactly says" (p.13). An example of this can be that of a speaker asking, "Did you get divorced?" and the other speaker replying, "You know, I think we married too young." By virtue of the reply of speaker two, the first speaker, even though she did not have a no for an answer, infers that the answer is definitely "yes, I got divorced." This is a way the speaker uses to disclose himself without giving the customary yes or no for an answer.

\subsection{The Importance of Pragmatics in English Language Teaching}

Context offers enough meaning to the difficult task of understanding oral communication. The decoding of the type and amount of pragmatic input determines the effectiveness of conversations in natural occurring environments. Pragmatics has recently gained relevance in the field of teaching. Recent studies on the field of pragmatics have proved that some EFL teachers have agreed upon the need of instructing learners to understand the effects of inappropriate language use and to know when and how to be polite, casual or authoritative. This learning of natural language use enables the speakers to interact effectively and keep the stream of communication flowing with neither hesitations nor misunderstandings. Providing that in an EFL context the amount of genuine interaction is limited or non-existing, teachers should facilitate opportunities to authentically help students take on different conversation roles in a wide variety of situations. In fact, Irun and Baiget (2006) demonstrated that the relevance of the teaching of pragmatics to EFL learners can be oriented towards four different pedagogic assumptions:

a. The development of socio-pragmatic competence is a key factor in the

b. process of learning a language. 
c. The L1 can be used in order to scaffold learners' development of a second or a foreign language.

d. Raising language awareness and promoting explicit knowledge about language can contribute to the development of language learners' proficiency.

e. Developing intercultural awareness is essential for learners to become good communicators in a foreign language, able to handle communicative exchanges with native and non-native users of English smoothly and effectively. (p.134)

The customary language teaching methodologies require a wider scope now. It is urgent to include pragmatics as a salient component of language teaching. Nonetheless, it is worth stating some pragmatic language learning problems EFL students face according to Derakhshan and Zangoei (2014):

The lack of varied, naturally occurring input in both EFL and ESL contexts

A lack of salience in the available input A lack of awareness about the forms, norms and limits and

A lack of direct or explicit feedback about violations of the norms in natural contexts or in textbook models (p.1655)

Textbooks and ordinary rote learning practices do not cater the real needs speakers face outside the classroom. The teaching of pragmatics may equip learners with more communication skills to create and interpret meaning by themselves. Although it is necessary, no one denies how difficult pragmatic instruction could be. Kasper (1997) assured that:
Can Pragmatic Competence Be Taught?' The simple answer to the question as formulated is "no". Competence, whether linguistic or pragmatic, is not teachable. Competence is a type of knowledge that learners possess, develop, acquire, use or lose. The challenge for foreign or second language teaching is whether we can arrange learning opportunities in such a way that they benefit the development of pragmatic competence in L2". (p. 22)

What teachers need to do is to facilitate the most realistic opportunities for students to grasp pragmatic skills. EFL teachers cannot handle pragmatics the same way they have used to teach grammar, lexicon or semantics, if that were the case. In the light of this urgent need, EFL instructors are called upon a reinvention of their own strategies to teach. They may need to be more creative and less traditional in the methodology and materials used. The development of pragmatic ability in the language classroom, regardless of how time-consuming it may be, must be approached as a process involving renewed techniques.

\subsection{The Use of Audio-visual Aids to Teach Pragmatics}

The use of audio-visual aids to make natural language possible in the EFL classroom has been an area of great concern nowadays. Teachers have found diverse benefits from culturally rich input fed to language learners through audio-visual aids. Some examples of these aids could be movies, news reports, TV advertisements, educational TV programs, movie trailers, video clips, talk shows, 
game shows, documentaries, reality shows, cartoons, TV series, sitcoms, sports shows, among others. It is worth recognizing that pragmalinguistic and sociopragmatic awareness are difficult to grasp for EFL learners. Thus, the use of audio-visual aids can be illustrative of one practical way for instructors to introduce more natural-occurring language samples in the actual context the conversations happen. It is a fact that an EFL classroom is a marginalized source of genuine target language forms. In this same vein, Derakhshan and Zangoei (2014) assured:

...due to scarcity of native speakers, naturalistic input is not accessible inside and outside the [EFL] classroom and sociolinguistic conventions involved in using the textbooks cannot simulate and authenticate real life situations; therefore, the use of video-driven prompts hold a great promise to bring real life to the classroom and to be able to raise learners' sociopragmatic and pragmalinguistic awareness. (p.1653)

These audio-visual aids might help teachers facilitate the learners' process of becoming more competent in communication by developing the ability to understand and perform action in the target language. In a rather similar line of inquiry, Derakhsan, Mohsenzadeh and Mohammadzadeh (2014) believed that "videotaped materials bring the closest approximation of real life situations to the classroom environment" (p. 17). This type of materials are the most realistic way for teachers to help learners come close to the locus of actual target language action. Therefore, teachers should lay stress on innovative techniques in order to enable learners to become communicatively competent in time.

\subsection{Allessi and Trollips' Principles to Aid the Transfer and Acquisition of Information}

Innovative teachers have put great premium upon the use of technology in the classroom and its diverse benefits in this digital era. More specifically, the use of videos have proved to be advantageous to the students' foreign language learning in several ways. Videos help learners perceive and understand target language forms in their actual environment. Natural language is studied from a more experiential approach rather than a simplistic presentation of language. Paralinguistic elements are also internalized more easily since learners make mental linkages while observing and relating. In other words, videos are rich sources of natural occurring input that expose learners to a wide variety of settings, sometimes in a single snapshot.

In order to learn from any type of audio-visual aid, especially in the form of video materials, Allesi and Trollip (2001) devised a framework constituted by some principles to facilitate the transfer and acquisition of new information. The first principle accounts for perception and attention. It refers to focusing attention on the information being displayed in the form of a video. It is the teachers' task to engage students thoroughly by using their senses to internalize the new knowledge. Encoding is the second principle of Allesi and Trollip's framework. For long-term learning to happen, the incoming information requires to be encoded, and 
later on, stored by the brain. In this phase, learners need to manipulate and use the information elicited from the video in order to prove understanding.

The third principle stands for the use of memory. Once the information has been encoded and understood, learners are led to trust their memory and retrieve more information. This information can be either specific or general. The most significant aspect in this phase is to guarantee that the information has been effectively stored. It can be achieved through two principles to maximize memory: the principle of organization and the principle of repetition (Fleming \& Levie, 1993, p.22).The last principle concerns to comprehension, the utmost goal of any communication-driven context. The learners are now prepared to demonstrate their understanding of the new knowledge by using it in an appropriate environment. Teachers are expected to fuel language use by providing opportunities and setting the right conditions for learners to produce as if in a natural context. Briefly, the language learning process, marked by the previous principles, can be optimized by the teaching of pragmatic skills through videos.

\section{Method}

There are two kinds target subjects in this study: freshmen and junior students of the English Teaching Major and their oral communication course teachers. Five language instructors and thirty-five learners provided the required data. A random sampling method was used to select them.

This study is qualitative in nature since the researchers sought to collect data in the field at the site participants experience the issue under study. Upclose information is gathered by talking directly to informants and seeing them behave and act within their context (Creswell, 2014, p. 185). Class observation and artifact collection were two qualitative instruments used. In fact, ten non-participative structured observations were conducted. Likewise, a questionnaire for teachers and one for students were also administered. Both questionnaires were divided into the same two main sections. The first part inquired data about the elements of pragmatics addressed in class. A ranking item was firstly introduced and then the second question required informants to describe, through a practical example, the way the principles outlined by Yule (1996) was treated. The second section gathered specific information about the use and types of videos usually brought to class. Informants listed the types of videos used and answered open questions regarding material and in-class exercises. The teachers' instrument had a final question that led them to identify the advantages and disadvantages of using videos as well as some implications of use.

A descriptive scope was followed since the researchers' intention was to describe the phenomena, situations, contexts, or events behind the research topic (Hernández, 2011: 80). In fact, the analysis of the data describes the informants' perceptions regarding the way pragmatics, and the use of videos to give meaning to words affect communication.

This study has three fundamental research questions: 
6. How do teachers approach pragmatics in oral communication courses?

7. How are videos used in oral communication courses?

8. To what extent are videos used to teach pragmatics in oral communication courses?

9. Findings.

An examination of students' and teachers' responses and data gathered drew the next analysis. Through the information provided in the questionnaires, students' revealed key data on how teachers approach videos and pragmatics in oral courses. These informants agreed that teachers do instruct some pragmatics' elements in class. Learners are guided to predict, focus on the speakers' act, focus on pointing of immediate context and identify the action behind words frequently. However, this practice is done in a really limited way. According to participants' choices in the questionnaire, the highest percentages for each pragmatic element are labeled as "rarely" and "never". In fact, Identifying messages/meaning was the element with the highest use. These results support the urge to pay more attention to pragmatics in class. Teachers were asked the same question, and they confirmed that focusing on the speaker's acts is the least addressed pragmatic element. On the contrary, teachers responded that identifying the message/meaning was the most addressed element. Indeed, this was confirmed through class observation. Teachers tended to give importance to this issue in most of the classes observed. Teachers also mentioned that focusing on pointing of immediate context and identifying the action behind words are two elements that catch teachers' attention.
Practical ways to treat pragmatics in class were noted down during the observations. None of them included the use of videos though. Teachers outlined practical examples for each pragmatic principle. In the case of deixis and distance, rephrasing ideas and using body language to clarify were listed. To address reference and inference the example provided was to make relationships between meaning and vocabulary. Presupposition is treated through critical analysis of texts, analysis of phrases/idioms, and direct analysis of contexts. Explicit analysis and discussions are the two examples on how teachers deal with implicature. When professors' responses were compared to behaviors observed, it was possible to determine that there is congruency between both. Moreover, it was observed that teachers tended to address some pragmatic principles through explicit explanations, which was the case of identifying the meaning/message, deixis and distance, reference and inference, and implicature.

Learners were also asked to list the types of videos mostly used. Their responses reveal (see Table 1) that teachers tend to rely more on movies, video clips and talk shows while TV series, sports shows and reality shows are not usually included in lesson plans. Through these responses, it can be concluded that there is a tendency to overuse the same type of material, which may be conducive to monotonous classes. This information was compared with teachers' responses and class observations. According to the options chosen by teachers in the questionnaire, they use video clips, ads, documentaries, TV series and movies in a high percentage. Observations 
confirmed these ideas; however, during the classes observed documentaries and video clips were never used.

Table 1

Types of Videos Used in Oral Communication Courses

\begin{tabular}{lcc}
\hline \multirow{2}{*}{ Type of videos } & \multicolumn{2}{c}{ Percentage } \\
\cline { 2 - 3 } & $\begin{array}{c}\text { Students' } \\
\text { responses }\end{array}$ & $\begin{array}{c}\text { Teacher's } \\
\text { responses }\end{array}$ \\
\hline Movies & $21,2 \%$ & $13,8 \%$ \\
Video clips & $16,9 \%$ & $13,8 \%$ \\
Talk shows & $14,5 \%$ & $5,5 \%$ \\
Ads & $11,5 \%$ & $11,1 \%$ \\
Movie trailers & $9,6 \%$ & $8,3 \%$ \\
News reports & $8,4 \%$ & $8,3 \%$ \\
Documentaries & $6 \%$ & $13,8 \%$ \\
Reality shows & $3,6 \%$ & $5,5 \%$ \\
TV series & $3 \%$ & $13,8 \%$ \\
Sports shows & $3 \%$ & $0 \%$ \\
Educational & $2,5 \%$ & $5,5 \%$ \\
programs & $100 \%$ & $100 \%$ \\
Total &
\end{tabular}

Note. This table includes responses from both informants: students and teachers. The total number of students was 35 . Only five teachers participated. The percentage corresponds to the number of times informants chose the types of videos.

In order to document the way these videos are developed in class, students were also questioned regarding the types of class activities that are usually accompanied by videos. The most frequent activities listed were discussions, note taking and summaries. These responses evidence that there is a lack of variety in regard to the way teachers address video analysis. Being this item an open-ended question, informants were free to provide as many activities as possible; however, their list was short. This information was compared to teachers' responses and the observations. Teachers' responses (see Figure 1) agreed with the students ones. They affirmed that there is an overuse of solving written items like matching, fill-in-the-blanks, true-and-false. During the observations, pre-activities like presenting a vocabulary bank and predicting events were recorded. Students were asked to summarize main ideas, answer oral comprehension questions and complete exercises in handouts.

\begin{tabular}{|c|c|c|}
\hline Students & Teachers & Observations \\
\hline $\begin{array}{l}\text { Macro / } \\
\text { micro group } \\
\text { discussion, } \\
\text { Nole taking, } \\
\text { Sumary, } \\
\text { Comprehen- } \\
\text { sion exercis- } \\
\text { es (written } \\
\text { items) }\end{array}$ & $\begin{array}{l}\text { Prediction } \\
\text { of events, } \\
\text { identifica- } \\
\text { tion of new } \\
\text { terms, Com- } \\
\text { prehesion } \\
\text { exercises } \\
\text { (written } \\
\text { items) }\end{array}$ & $\begin{array}{l}\text { Presentation } \\
\text { of vocabulary, } \\
\text { Prediction of } \\
\text { events, Sum- } \\
\text { mary, answer } \\
\text { oral questions, } \\
\text { Comprehen- } \\
\text { sion exercises } \\
\text { (written items) }\end{array}$ \\
\hline
\end{tabular}

Figure 1. Video-based activities and exercises usually done in class. This information was taken from question $\mathrm{B}$, section 2 in the questionnaire for students, question $\mathrm{B}$, section 2 in the questionnaire for teachers and class observations.

Also important was to research the type of material used during video-based activities. Students agreed that teachers tend to bring to class comprehension worksheets in a high frequency. Learners listed projector, images and newsprint as well. The last two are used to report information taken from videos. Teachers listed the same material and included props, realia and notebooks. During the observations, the materials used were all the necessary equipment 
to project a video, printed handouts, the board and paper to draw.

Teachers were asked to identify the main advantage of using videos. They all agreed that videos could increase input through arousing student interest in English. This decision evidences that they tend to minimize the role of videos to approach pragmatics. Instead, they give more attention to the motivational element behind the use of interesting material. Videos should have other linguistic purposes than just being a source of motivation. It was revealed that few pragmatic principles are approached in class, and when it is done, it is mostly done through direct explanations. Additionally, the treatment given to pragmatics through the use of videos is limited. There is no variety of class activities. Also, the role of videos in the language class showed to be influenced by other interests rather than the connotative meaning of words.

\section{Proposal}

The implications of this study yielded valuable information for EFL instruction. After analyzing the data garnered and the literature examined, the results brought forward several valuable aspects. First, professors in this major do not use a specified approach to interweave the use of videos with the teaching of pragmatics. Second, there was not a structured format to use videos in order to foster the teaching of pragmatics in the EFL classroom.

The researchers considered the main findings derived from the previous study to design an enlightening proposal in order to teach pragmatics to EFL students through the use of audiovisual aids. In this regard, the proposal sheds light upon the need of integrating pragmatics to the teaching of the connotative meaning of English words and phrases using the realistic and culturally rich language portrayed in video clips. It is worth mentioning that the proposal entails a frame based on Alessi and Trollips' four steps (2001) to transferring and acquiring information: perception and attention, encoding, memory and comprehension. This is an attempt at raising students' awareness towards the understanding of the deep meaning of lexicon and utterances heard.

In the perception and attention phase, natural-occurring language used in authentic communication by using videos is brought to conscience. Teachers are supposed to select any type of video clip where social interaction takes place such as movie trailers, advertisements, sitcoms among others and make them fit into this framework. Video clips in the form of visual and aural stimuli facilitate the accumulation of information for further understanding and use.

In the encoding stage, learners' attention is brought to specific titbits of information. The information students will elicit from the video will be prepared to be stored in the brain by being manipulated and transformed into more digestible pieces. The learners are asked to provide detailed data from the scenes watched.

Concerning the memory stage, learners are required to step back, without watching the video again, and recall one scene, word or phrase in the video clip. Information that demands more concentration, attention, practice or organization is supposed to last longer in the learners' memory. 
At the end of this framework for acquiring and processing knowledge lies the comprehension stage. During this stage, students demonstrate how effectively they handle the information they have grasped by performing the activities the teacher designed to facilitate the understanding of non-literal meaning and develop a "feel" for what lies beyond words.

Each worksheet is used as a separate entry for a students' diary about teaching pragmatics through videos. Learners compile all the entries that the teacher gives them and bind the whole set of worksheets together. This is the reason why every worksheet for each different video is numbered.

Note: This statement confirms that the design and layout of the following worksheets about the implementation of the framework derived from Alessi and Trollip's principles to transfer and acquire information are an authentic and original work by Cinthya Olivares Garita and Lena Barrantes Elizondo for the sole purpose of teaching pragmatics through the use of video clips in the EFL classroom.

\section{Bibliography}

Alessi, S. \& Trollip. S. Multimedia for learning: Methods and development. Boston: Allyn \& Bacon, Incorporated, 2001.

Barron, Anne. Acquisition in interlanguage pragmatics: Learning how to do things with words in a study abroad context. Philadelphia: John Benjamins Publishing Company, 2003.

Creswell, J. Research design. California: Sage, 2014.
Derakhshan, A. \& Zangoei, A. Video driven prompts: A viable pragmatic consciousness-raising approach in EFL/ESL classrooms. World Applied Sciences Journal, 31, 13, 2014.

Derakhshan, A., Mohsenzadeh, H., \& Mohammadzadeh, S. (2014). The nuts and bolts of teaching implicatures in EFL/ESL contexts: An overview on the role of video-enhanced input. International Journal of Applied Linguistics and English Literature, 3 (5), 1663-1655, 2014.

Fleming, M. \& Levie, W. Instructional message design: Principles from the behavioural and cognitive sciences. New Jersey: Educational Technology, 1993

Hernández, R. Fernández, C. \& Baptista, P. Metodología de la investigación. México: McGraw Hill Interamericana, 2011.

Irun, M. \& Baiget, E. Raising awareness of pragmatics in the EFL classroom: A proposal. Revista de Estudios Culturales de la Universitat Jaume I, 3, 133-144, 2006.

Kasper, Gabriele (Editor). Interlanguage pragmatics. NC: Oxford University Press Incorporated, 1993.

Kasper, Gabriele. Can pragmatic competence be taught? NetWork, MA: Allyn \& Bacon, 1997.

Potts, C. Presupposition and implicature. The Handbook of Contemporary Semantic Theory. 2nd. ed., 168-202. Oxford: Wiley-Blackwell, 2014.

Stalnaker, C. Context and content. New York: Oxford University. Press, 1999. Yule, G. Pragmatics. New York: Oxford University Press, 1996. 


\section{Appendix}

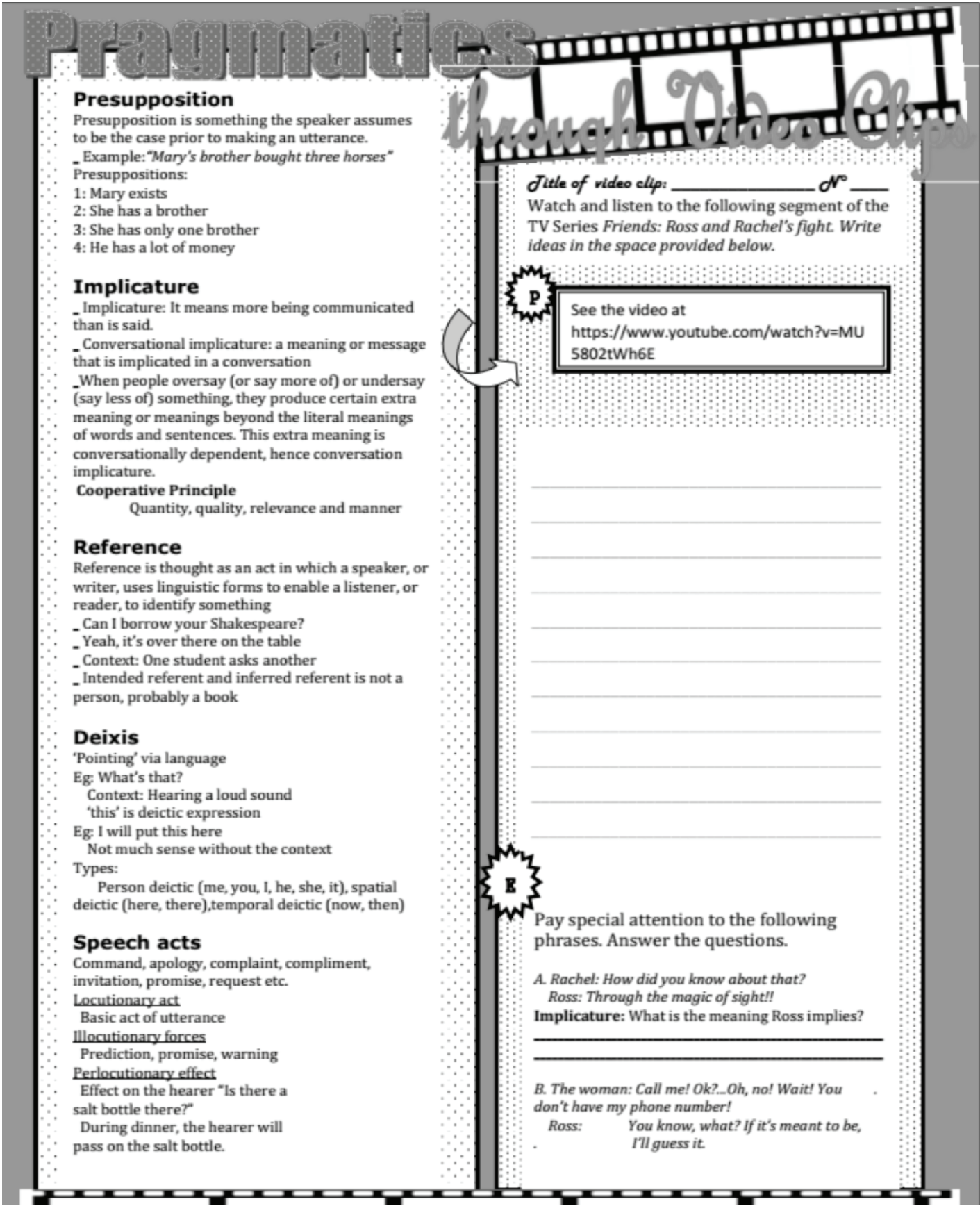


Implicature: What is the message Ross intends to get across when he says "If it's meant to be, I'll guess it."

\section{Ross: Oh, really?}

Rachel: Yeah!

Ross: Oh, really?

Rachel: Oh, yeah!!

Speech acts: Why do the speakers repeat the same words with different intonation? What are they trying to say?

D. Rachel: We said we would live together as long as this makes sense... and ah...Maybe this ..you know...just doesn't make sense anymore.

Ross: Yeah...maybe not. So what do you wanna do? Joe: Hey!

Rachel: Hi! Can Emma and I live here for a while? Joe: A hard time!!

What does the audience implies when Joe opens the door and greets Rachel? What does the phrase "A hard time?!" implicate?

\section{$\circ$}

Recall what the woman says to Ross in the scene below. What do you remember Ross sarcastically replies to her?

\begin{tabular}{l}
\hline See the video at \\
https://WwW.youtube.com/watch? $v=M U$ \\
58ח?+WhhF
\end{tabular}

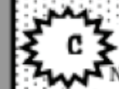

W, it's your time to choose one of the

phrases studied here and put it into a new context.

Write your script in the space provided below. Act

it out! 